\title{
Control of belching by the lower oesophageal sphincter
}

\author{
J B Wyman, J Dent, R Heddle, W J Dodds, J Toouli, J Downton
}

\begin{abstract}
The mechanism that controls venting of gas from the stomach into the oesophagus was studied manometrically in 14 healthy subjects. The stomach was distended abruptly with one litre of carbon dioxide. Gas reflux was characterised by an abrupt increase in basal oesophageal body pressure to intragastric pressure. Reflux of gas from the stomach into the oesophagus occurred during transient lower oesophageal sphincter relaxations that generally had a pattern distinctly different from swallow-induced lower oesophageal sphincter relaxation. Thus, at the onset of an episode of gas reflux lower oesophageal sphincter pressure had relaxed to $3 \mathrm{mmHg}$, or less, in $96 \%$ of instances. After gas loading of the stomach the prevalence of gas reflux was significantly less when the subjects were supine $(1.2 / 10 \mathrm{~min})$ than when they were sitting $(6 \cdot 8 / 10 \mathrm{~min})(\mathrm{p}<0 \cdot 001)$. The lower oesophageal sphincter relaxations associated with most episodes of gas reflux had a distinctive pattern that resembled those of the lower oesophageal sphincter relaxations associated with acid gastro-oesophageal reflux.
\end{abstract}

The mechanisms that govern the retrograde escape of gas from the stomach into the oesophagus in association with belching have received little attention. The phenomenon of gastrooesophageal reflux of gas was first studied in humans by McNally, Kelly, and Ingelfinger.' The scope of their observations, however, was severely limited by the suboptimal manometric instrumentation available at the time. Based on only a few observations, these authors proposed that gas gastro-oesophageal reflux occurred during reflex inhibition of lower oesophageal sphincter tone. Recently, Kahrilas et $a l^{2}$ examined the physiology of upper oesophageal sphincter function associated with belching but detailed analysis was not provided of lower oesophageal sphincter participation. Current evidence suggests that gastro-oesophageal reflux of acid generally occurs during transient relaxations of the lower oesophageal sphincter that are not induced by swallowing. ${ }^{3-6}$ The transient lower oesophageal sphincter relaxations associated with acid gastro-oesophageal reflux resemble those described in the study of gas reflux by McNally et al.' The aim of this study was to determine whether gastro-oesophageal reflux of gas occurs by the same or similar phenomenon of non-deglutitive lower oesophageal sphincter relaxation that is a prevalent mechanism of acid reflux.

\section{Method}

We studied 14 fasted healthy volunteers, aged 19-49 years (median 24 years). Subjects who had heartburn or regurgitation more than once every two weeks were excluded. The study protocol was approved by the Ethical Review Committee of Flinders Medical Centre in April 1983.

A manometric sleeve assembly ${ }^{7}$ and an intraluminal $\mathrm{pH}$ electrode were passed transnasally and positioned so that the sleeve straddled the lower oesophageal sphincter and the electrode $5 \mathrm{~cm}$ proximal to this. The subject then sat for a 10 minute period to adapt to the equipment. Oesophageal motility and oesophageal $\mathrm{pH}$ were then recorded in seven sequential 10 minute periods, as shown in Figure 1. Apart from the five to 10 minute interval between periods 5 and 6 , the time between other measurement periods was minimal, with only $30-60$ seconds needed to change body position or to give a gas-generating mixture.

Gas was generated by oral administration of two solutions that combined in the stomach to form $\mathrm{CO}_{2}$ (Field Negative C, Field Group Chemicals Pty Ltd, Sydney, NSW, Australia). This method of $\mathrm{CO}_{2}$ delivery was used because it was a simple, reproducible way of producing abrupt gastric gaseous distention. Firstly, $10 \mathrm{ml}$
GI Unit, Royal Adelaide Hospital, Adelaide, South Australia 5000 J B Wyman J Dent R Heddle

W J Dodds

J Toouli

J Downton

Correspondence to: Dr John Dent, Director, G Unit, Royal Adelaide Hospital, North Terrace Adelaide, South Australia 5000 , Australia.

Accepted for publication 28 August 1989

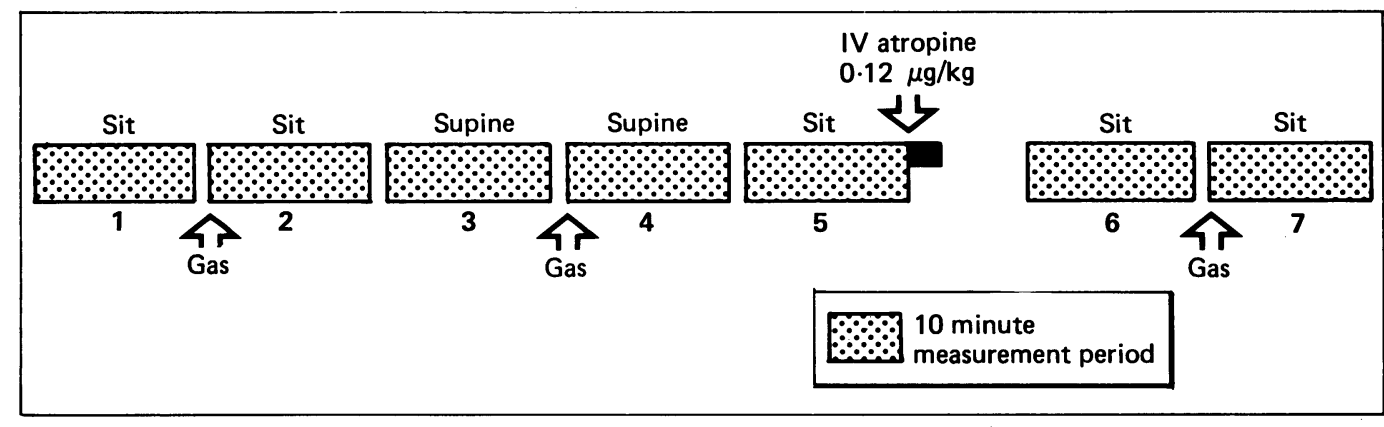

Figure 1: Protocol for posture, gastric gas loading, and atropine administration during manometric and oesophageal pH recordings. 


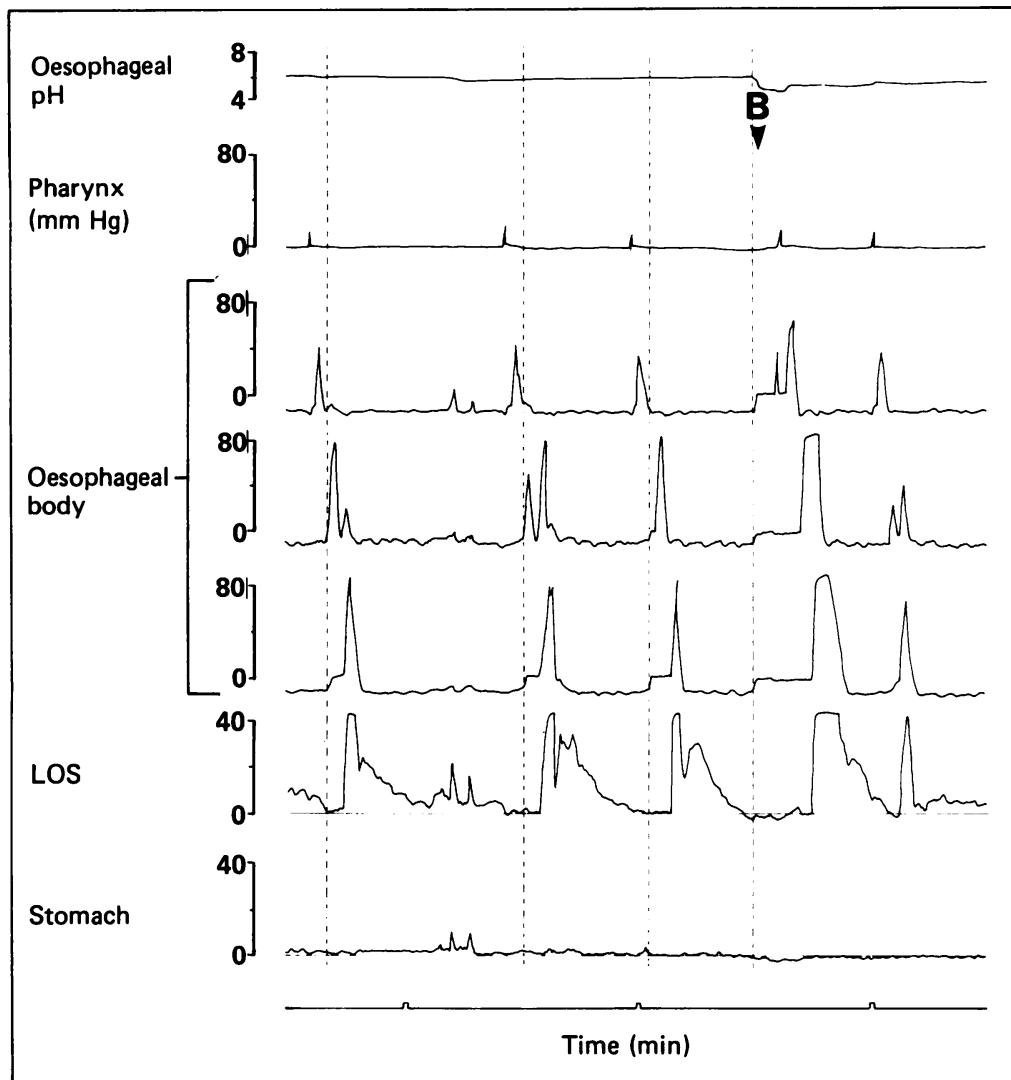

Figure 2: Manometric and $p H$ tracing during several episodes of gastro-oesophageal reflux of gas (GOR) after gastric gas loading. At the first vertical dotted line, gas GOR occurred during a normal swallow-induced lower oesophageal sphincter relaxation (LOSR) but the pressure increase was limited to the distal oesophagus. The intra-oesophageal pressure increase was eliminated when primary peristalsis returned refluxed gas to the stomach. At the second and third dotted lines LOSR occurred just before swallowing but the interval between the relaxation and swallowing was so short that the possibility exists that the relaxation was due to swallowing. In this episode also, swallow-induced oesophageal peristalsis limited upward flow of gas in the oesophageal body. At the fourth dotted line, gas oesophagopharyngeal reflux occurred during a transient LOSR that is clearly unrelated to swallowing. Gas flow into the upper oesophagus was followed by an audible episode of gas oesophagopharyngeal reflux as indicated by a belch $(B)$. A slight reduction of basal gastric pressure occurred during this common cavity episode, accompanied by a small decrease in oesophageal $p H$. The common cavity pressure within the oesophagus was cleared by primary peristalsis. The duration of all transient LOSRs associated with gas GOR were substantially longer than the LOSRs associated with a partial primary peristaltic sequence, seen at the end of the tracing.

Figure 3: Rate of common cavity episodes for each 10 minute test period, according to posture and timing of gas loading. Values given as mean $(S E)$. Results for seven studies with and seven studies without surfactant. Mean common cavity rates for all 14 subjects are given in text.



shown by bench testing, the solutions produced one litre of $\mathrm{CO}_{2}$ within 10 seconds that had a $\mathrm{pH}$ of 6.3 after effervescence stopped. The generated gas tended to be trapped in a foam. In the last seven subjects studied, foaming was suppressed by adding $2 \mathrm{ml}$ of surfactant to solution 1 (Bubble Breaker, Field Group Chemicals Pty Ltd, Sydney, NSW, Australia). Atropine (David Bull Laboratories, Mulgrave, Victoria, Australia), given before period 6 (Fig 1), was injected intravenously during a two minute interval, at a dose of $12 \mu \mathrm{g} / \mathrm{kg}$. The subjects were instructed to signal the occurrence of, or the urge for gas oesophagopharyngeal reflux and were asked to avoid straining.

A 7 lumen manometric sleeve catheter was positioned so its $6 \mathrm{~cm}$ long sleeve sensor ${ }^{7}$ straddled the lower oesophageal sphincter. Two channels recorded upper gastric pressure via side holes positioned 1 and $2.5 \mathrm{~cm}$ below the distal sleeve margin. Oesophageal body motility was monitored with side holes at the proximal sleeve margin, and at 5 and $20 \mathrm{~cm}$ proximal to the sleeve. A side hole positioned in the pharynx monitored swallowing. A hydraulic system perfused the sleeve with distilled water at $1 \mathrm{ml} / \mathrm{min}$. The pharyngeal channel, perfused at $0.1 \mathrm{ml} / \mathrm{min}$ gave a satisfactory swallow signal. All other manometric channels were infused at $0.5 \mathrm{ml}$ min. After each study, the baseline of each manometric channel was determined with the perfusion on, both with the catheter horizontal on a bench and hanging vertically. This procedure allowed accurate comparison of pressures in different channels when the subject was in the supine and sitting positions. Oesophageal $\mathrm{pH}$ recordings were made with a Beckman monopolar glass $\mathrm{pH}$ electrode (model 39042) located $5 \mathrm{~cm}$ above the lower oesophageal sphincter. An external reference electrode was taped to the forearm. Calibration of the $\mathrm{pH}$ electrode was checked with buffers of $\mathrm{pH} 4$ and 7. Signals from the $\mathrm{pH}$ meter (Electronic Instruments Ltd, model 2320) and the pressure transducers were amplified and recorded by a Devices M19 8-channel polygraph run at a speed of $250 \mathrm{~mm} /$ $\min$

We used the selective terms gas gastrooesophageal reflux and gas oesophagopharyngeal reflux. Belching consists of both types of reflux, while gas oesophagopharyngeal reflux alone is referred to as an oesophageal belch. To identify gas gastro-oesophageal reflux, we used common cavity episodes as a marker. For our purpose, we defined a common cavity episode as an abrupt increase in intra-oesophageal body pressure to intragastric pressure in at least the two lower oesophageal body manometric recording sites (Fig 2). This pattern of pressure changes is a generally accepted marker of gas or liquid reflux from the stomach into the oesophagus. ${ }^{1-689}$ The pressure tracings were scanned for common cavity episodes that fulfilled the above criteria. Any oesophageal $\mathrm{pH}$ changes associated with each episode of gas gastro-oesophageal reflux were measured at five seconds before and five seconds after the onset of the common cavity episode. Lower oesophageal sphincter pressure was measured at the onset of each common cavity episode. The relation between swallowing and 

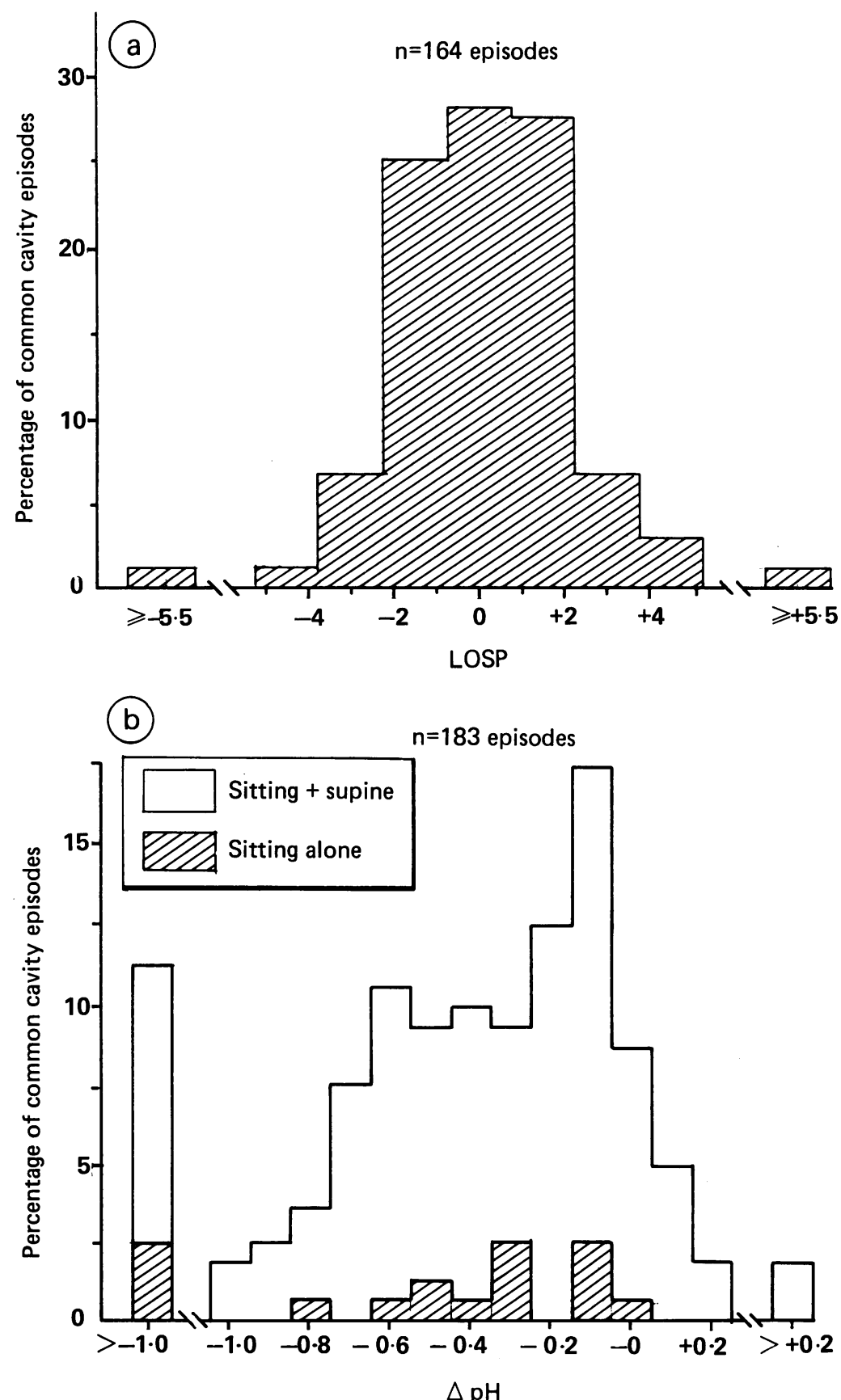

Figure 4: Relation between oesophageal body common cavity episodes and lower oesophageal sphincter pressure (LOSP) and changes in oesophageal $p H$. (a) LOSP at onset of 164 interpretable common cacity episodes. (b) Oesophageal $p H$ changes five seconds after onset of common cavity episodes, referenced to oesophageal $p H$ five seconds before the onset of the common cavity episode. of pharyngeal and oesophageal body motor events.

The duration of each lower oesophageal sphincter relaxation associated with a common cavity episode was measured from the sleeve tracing as the time between the onset of maximal lower oesophageal sphincter relaxation and the start of the upstroke of the pressure wave which ended sphincter relaxation. Response of gastric pressure to gas loading in the supine position was measured by sampling end-expiratory gastric pressure at 15 second intervals for one minute before and 10 minutes after giving the gasproducing mixture. Gastric pressure changes were analysed only for the gas distentions in the supine position because the height of the subjects was constant relative to the extra-luminal transducers throughout the measurement period while in the erect position minor positional changes occurred that may have altered the level of the recording sites relative to the recording transducer. Transient pressure changes caused by straining were excluded from this analysis of gastric pressure. The relation between abdominal straining and the onset of common cavity episodes, however, was examined by scoring any strain-related increase in intragastric pressure that was present at the beginning of a common cavity episode. Basal lower oesophageal sphincter pressure just before and 10 minutes after giving atropine was determined visually as one minute mean values. Statistical analysis was done by the Wilcoxon rank sum test for paired and unpaired data. Averaged values are given as mean (SE).

\section{Results}

RELATION BETWEEN POSTURE AND OCCURRENCE OF COMMON CAVITY EPISODES

After gas administration, the rate of common cavity episodes was dependent on subject posture (Fig 3). The posture effect was consistent among subjects, regardless of whether or not surfactant was used. Thus, data from all 14 studies were pooled. The mean highest common cavity rate of $6.8(0.8) / 10 \mathrm{~min}$ occurred directly after loading with the subject sitting (Figs 1 and $3)$. This rate was greater than the low rate of $1 \cdot 2(0 \cdot 3) / 10 \mathrm{~min}$ that occurred directly after gas loading, when the subjects were supine $(p<0.001)$. In the 10 minute period after the subject sat up, the rate of common cavity episodes rose significantly to $4 \cdot 5(0 \cdot 6) / 10 \mathrm{~min}$ without further gas loading $(\mathrm{p}<0 \cdot 001)$. During periods 2 and $5,48 \%$ and $52 \%$ respectively of the common cavity episodes occurred within the first three minutes.

\section{LOWER OESOPHAGEAL SPHINCTER}

PRESSURE ASSOCIATED WITH ONSET OF COMMON CAVITY EPISODES

In 164 of 183 common cavity episodes the lower oesophageal sphincter pressure tracings were interpretable at the onset of the oesophageal body common cavity episode. As summarised in Figure 4a, lower oesophageal sphincter pressure oesophageal sphincter relaxation. Non-d titive lower oesophageal sphincter relaxations termed transient lower oesophageal sphincter relaxations. The mechanisms responsible for resolution of oesophageal body common cavity episodes after reflux were determined by analysis 
Oesophageal body motor events associated with termination of oesophageal body common cavity pressure

\begin{tabular}{lc}
\hline Oesophageal body activity & $N o(\%)$ \\
\hline Secondary peristalsis & $87(49)$ \\
Primary peristalsis & $76(43)$ \\
Synchronous contraction & $7(4)$ \\
No identifiable contraction & $7(4)$ \\
\hline
\end{tabular}

Only common cavity episodes recorded in at least the two distal oesophageal body recording points are included in the analysis. The timing of termination of common cavity pressure was determined from the distal oesophageal body recording site.

was low or unrecordable at the beginning of a common cavity episode. Low or absent lower oesophageal sphincter pressure at the moment of gas gastro-oesophageal reflux was due to a swallow-induced or transient lower oesophageal sphincter relaxation, rather than a prolonged reduction in lower oesophageal sphincter pressure. In 26 of the 183 common cavity episodes, pharyngeal or oesophageal motor events were either too numerous to allow detailed analysis of pharyngo-oesophageal motor patterns immediately beforehand or were obscured by movement artifact. Among the interpretable common cavity episodes, the most common cause of gas gastro-oesophageal reflux was a transient lower oesophageal sphincter relaxation that occurred without any recorded prior pharyngo-oesophageal motor event. These spontaneous transient lower oesophageal sphincter relaxations accounted for $38 \%$ of the interpretable episodes. Other patterns of lower oesophageal sphincter relaxation associated with gas gastro-oesophageal reflux are shown in Figure 2. Generally, the transient lower oesophageal sphincter relaxation was fully established for one to three seconds before the onset of a common cavity episode (Fig 2). The mean duration of the transient lower oesophageal sphincter relaxations associated with gas gastro-oesophageal reflux was $12.3(0.4) \mathrm{s}$. This exceeded the two to four second duration of the lower oesophageal sphincter relaxation nadir associated with a normal peristaltic sequence (Fig 2). The four most common patterns of lower oesophageal sphincter relaxation, which accounted for $86 \%$ of common cavity episodes are shown schematically in Figure 5. Gas gastro-oesophageal reflux that resulted in an identifiable common cavity episode seldom occurred during the brief two to four second nadir in lower oesophageal sphincter relaxation elicited by spontaneous swallowing.

The close correlation between the occurrence beforehand of a non-deglutitive transient lower oesophageal sphincter relaxation and the development of a common cavity episode held for both the supine and sitting positions. Thus, the low rate of common cavity episodes observed in the supine position reflected an infrequent occurrence of transient lower oesophageal sphincter relaxations.

\section{OESOPHAGEAL PH ASSOCIATED WITH COMMON CAVITY EPISODES}

Gas gastro-oesophageal reflux was usually associated with only small reductions in oesophageal $\mathrm{pH}$ (Fig 4b). The mean pH changes associated with common cavity episodes in the erect and supine positions were $0.32(0.03)$ and $0.48(0.12)$ pH units, respectively.

\section{ASSOCIATION OF GAS GASTRO-} OESOPHAGEAL REFLUX WITH COMMON CAVITY EPISODES

During $75 \%$ of the common cavity episodes either gas oesophagopharyngeal reflux occurred or the subjects perceived an urge to vent gas into their pharynx. When the abrupt increases in pressure were confined to the lower half of the oesophagus they were not associated with either gas oesophagopharyngeal reflux or the urge to vent gas (Fig 2).
Figure 5: Schema of the four most common patterns of lower oesophageal sphincter relaxation (LOSR) associated with gastrooesophageal reflux of gas $(G O R)$. Dotted lines indicate onset of common cavity episodes. Numbers across the bottom indicate percentage of interpretable gas GOR episodes produced by the pattern of LOSR shown above. Pattern A termed spontaneous. ${ }^{34}$ In pattern C, transient LOSR follows directly after $a$ normal peristaltic sequence (see Figure 2). In patterns $B$ and $D$, the LOSR that lead to gas GOR start concurrent with swallowing. In pattern $B$, swallowing could be a chance association with LOSR, wherein failure of oesophageal peristalsis was caused by oesophageal body inhibition associated with the transient LOSR. In pattern $D$, gas GOR occurs during LOSR associated with a normal primary peristaltic sequence. UOS $=$ upper oesophageal sphincter.




RESOLUTION OF COMMON CAVITY

PRESSURE

The duration of common cavity pressure increases in the distal oesophageal body varied from 2 to 63 seconds (mean $11 \cdot 4(0 \cdot 5)$ ). After a common cavity episode occurred the duration of increased intra-oesophageal pressure related directly to the interval that the lower oesophageal sphincter relaxation persisted. Both the lower oesophageal sphincter relaxations and common cavity episodes were usually terminated by secondary oesophageal body peristalsis (Fig 2). Occasionally, the lower oesophageal sphincter contraction preceded the oesophageal body peristaltic wave, in which case the common cavity pressure persisted longer than the lower oesophageal sphincter relaxation. The patterns of oesophageal contraction that resolved common cavity pressure are summarised in the Table. In the absence of oesophageal body contraction, the onset of a common cavity episode was virtually simultaneous at all sites at which the common cavity pressure was recorded. When a common cavity episode occurred during oesophageal body peristalsis the orad increase in intraoesophageal pressure extended as far as the advancing peristaltic wave (Fig 2). This phenomenon generally restricted the common cavity pressure to the distal oesophageal body. As the analysis of common cavity episodes required that they occur in at least two oesophageal body recording sites, episodes of gas gastrooesophageal reflux recorded at only the distal recording site were not included in the analysis, even though they occurred only when the lower oesophageal sphincter relaxed. Only $6 \%$ of the common cavity episodes that extended to the middle oesophageal body recording site met an advancing peristaltic wave that prevented extension of the common cavity to the upper oesophagus.

\section{GASTRIC PRESSURE CHANGES}

Gas loading increased intragastric pressure in all subjects. The mean peak increase of $4.4(0.6)$ mmHg occurred 30 seconds after administration of the gas-generating mixture. The magnitude of oesophageal body common cavity pressure corresponded to the intragastric pressure. Thus, the pressure increases associated with common cavity episodes were greatest directly after gas loading. At the onset of some common cavity episodes a brief drop in gastric pressure occurred followed by a rise in gastric pressure, presumably caused by the return of gas to the stomach by oesophageal peristalsis (Fig 2). Brief increases in intragastric pressure occurred at infrequent intervals during abdominal straining when subjects adjusted their body position. Abdominal straining, however, was not essential for initiation of gas gastro-oesophageal reflux (Fig 2) because straining was associated with the onset of only 37 of the $183(26 \%)$ common cavity episodes. Sixteen of these strain-related episodes of gas gastro-oesophageal reflux occurred in one subject, who strained consistently when he felt the need to vent gas into the pharynx. The lower oesophageal sphincter pressure tracing during these episodes was not interpretable. In other subjects the tracing was usually interpretable during straining, and in all but one episode,

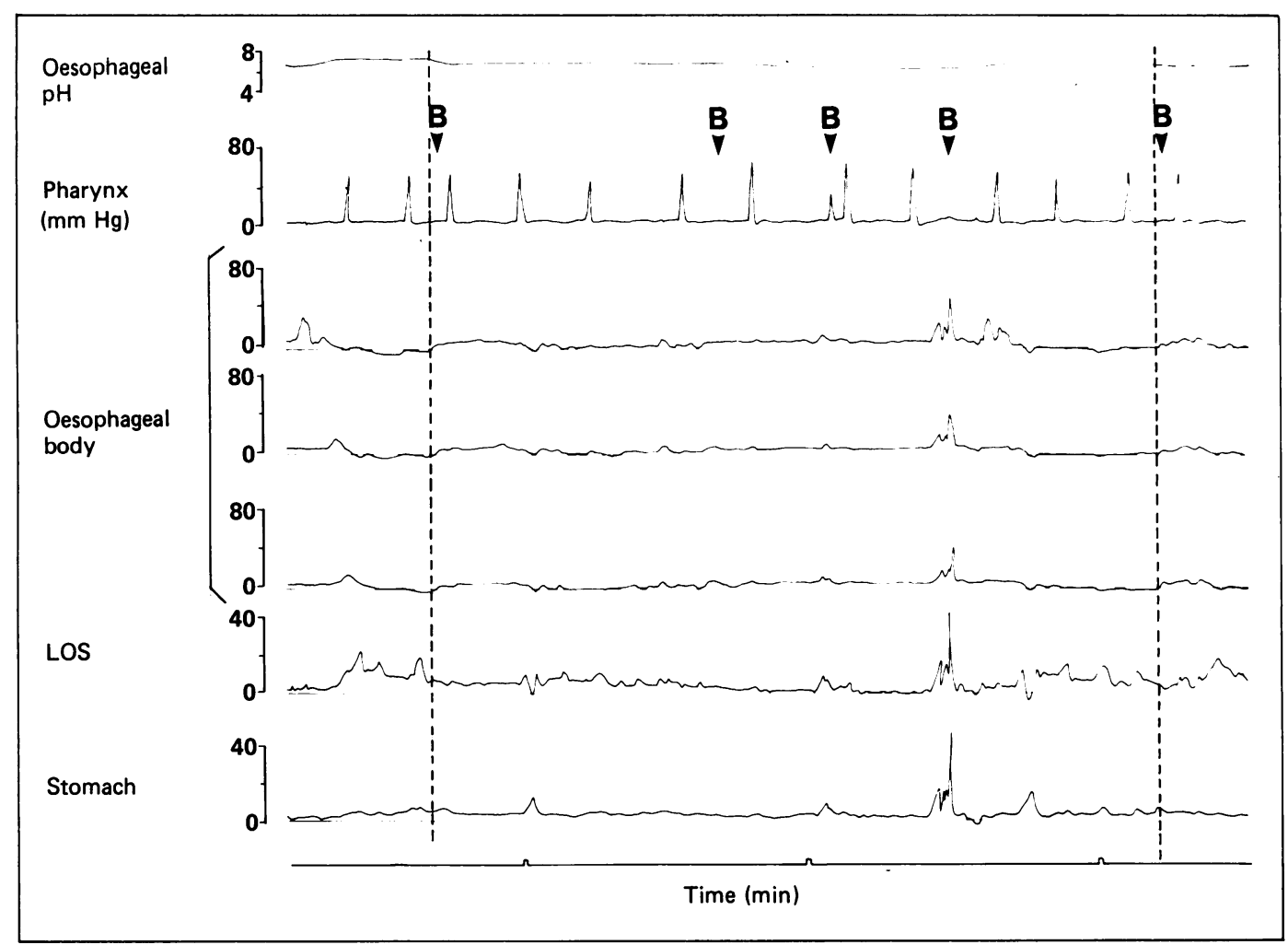

Figure 6: Pressure recording after atropine. Gas oesophagopharyngeal reflux, or belches, are indicated by a ' $B$ '. Vertical dotted lines indicate gas gastro-oesophageal reflux (GOR). An episode of gas GOR is seen on the left. During the prolonged increase of intra-oesophageal pressure multiple episodes of gas GOR probably occur but clearance of the initial refluxed gas is defective due to absence of peristalsis, caused by atropine. Gas oesophagopharyngeal reflux and a spike-like strain occur simultaneously in the third minute of recording. A further episode of gas GOR and oesophagopharyngeal reflux occurs at the vertical dotted line on the right of the figure. 
lower oesophageal sphincter pressure was $<3$ $\mathrm{mmHg}$ at the onset of the common cavity episode.

AFTER ATROPINE ADMINISTRATION

Before gas administration, atropine $(12 \mu \mathrm{g} / \mathrm{kg})$ reduced mean lower oesophageal sphincter pressure from $12 \cdot 1(2 \cdot 5)$ to $3 \cdot 2(0 \cdot 9) \mathrm{mmHg}$. Despite the atropine-induced sphincter hypotonicity, sufficient basal lower oesophageal sphincter pressure existed in some subjects to allow recognition of transient lower oesophageal sphincter relaxations after gas loading. In other subjects an initial relaxation resulted in a prolonged increase in oesophageal pressure due to failure of oesophageal clearance secondary to atropine-induced impairment of oesophageal peristalsis (Fig 6). In this circumstance the subjects perceived oesophageal distention and swallowed frequently in an attempt to clear the oesophagus. Occasionally, successful peristalsis cleared the oesophagus but then a further relaxation of the lower oesophageal sphincter led to recurrence of a common cavity episode. In these cases, gas oesophagopharyngeal reflux occurred at frequent intervals.

\section{Discussion}

This study was designed to generate and characterise the events that control orad venting of gas from the stomach. Our study findings show that:

(1) Gas gastro-oesophageal reflux is provoked by distending the stomach with gas;

(2) Gas gastro-oesophageal reflux occurs mainly during non-deglutitive transient relaxation of the lower oesophageal sphincter;

(3) Only a minority of episodes of gas gastrooesophageal reflux is associated with abdomina straining;

(4) Non-deglutitive transient lower oesophageal sphincter relaxations are subject to postura control, occurring more frequently in the upright than the supine position;

(5) Gas refluxed into the oesophagus is cleared mainly by oesophageal peristalsis.

Little data are available on lower oesophageal sphincter activity associated with gas gastrooesophageal reflux. ${ }^{12}$ Recently, Kahrilas $e t a l^{2}$ reported the physiological events underlying belching, but focussed mainly on the upper rather than the lower oesophageal sphincter. Initial observations about gastro-oesophagea events that accompanied gas gastro-oesophageal reflux were reported by McNally and coworkers in $1964 .{ }^{1}$ On the basis of only a few observations using non-infused manometric instrumentation, these authors observed that gastro-oesophageal reflux of gas occurred during a transient decrease in lower oesophageal sphincter pressure. The authors, aware of the problem of maintaining a recording orifice in the region of maximal lower oesophageal sphincter pressure, judged that they achieved satisfactory recordings in only a few episodes of gastro-oesophageal reflux. During gas gastro-oesophageal reflux, the lower oesophageal sphincter pressure decreased, a finding that led to the suggestion that inhibition of this sphincter underlies gas reflux. Although it is probable that the original lower oesophageal sphincter pressure recordings interpreted by McNally and coworkers were partially artifactual due to axial lower oesophageal sphincter movement, the findings of our study confirm and extend their main conclusions. The instrumentation and techniques used in this study allow comprehensive analysis of the manometric phenomena associated with gas gastro-oesophageal reflux of gas. When positioned straddling the lower oesophageal sphincter, the sleeve sensor monitors this pressure accurately, even though the sphincter moves axially along the sleeve. ${ }^{70}$ The recording sites along the manometric assembly also monitored swallowing, oesophageal body pressure activity, and gastric pressure while the $\mathrm{pH}$ electrode in the distal oesophagus detected gastro-oesophageal reflux of acid.

For analysis we relied on common cavity episodes as a marker of gastro-oesophageal reflux gas. Previous studies support the validity of oesophageal body common cavity episodes as an indicator of gastro-oesophageal reflux of gas or liquid. ${ }^{125689}$ McNally et al ${ }^{1}$ confirmed by cineradiography that oesophageal body common cavity episodes occurred concurrently with oesophageal distention caused by gastro-oesophageal reflux of gas. In this study, most oesophageal body common cavity episodes elicited by gastric loading with gas were accompanied by minimal drops in oesophageal $\mathrm{pH}$, oesophagopharyngeal reflux of gas, or the urge to vent gas into the pharynx. In an earlier study in healthy supine subjects, $82 \%$ of spontaneous episodes of acid gastro-oesophageal reflux were associated with a detectable common cavity episode. ${ }^{3}$ The common cavity phenomenon probably depends on sufficient distension of the oesophageal body by gas, liquid, or both to fill the oesophagus until its passive wall tension increases. In this study, the lack of appreciable reductions in $\mathrm{pH}$ associated with the common cavity episodes suggests the occurrence of essentially pure gas gastrooesophageal reflux, because even very small amounts of acid produce substantial oesophageal body acidification. ${ }^{11}$ This finding probably results from the large volume of gas placed in the stomach (one litre) relative to a small amount of acid that is present during fasting.

In our subjects, common cavity episodes confined to the lower oesophagus by an oncoming peristaltic contraction were not associated with either the occurrence of, or urge for gas oesophagopharyngeal reflux. This finding suggests that the sensation for oesophagopharyngeal reflux of gas is elicited by distention of the proximal oesophagus.

In this study, most $(51 \%)$ episodes of gastrooesophageal reflux of gas occurred during transient relaxations in the lower oesophageal sphincter that were unrelated to swallowing (Fig 5 , patterns A and C). Only $8 \%$ of the episodes of gastro-oesophageal reflux of gas occurred during the normal swallow-induced relaxation of the lower oesophageal sphincter associated with an intact peristaltic sequence that traversed the entire oesophagus (pattern D). In the case of pattern B (Fig 5), the transient lower oesophageal 
sphincter relaxation may have been triggered by swallowing, or the swallow may have been a chance association with a non-deglutitive transient sphincter relaxation. The associated failure of oesophageal body peristalsis in pattern B supports this latter interpretation, because active inhibition of the distal oesophageal body has been reported to occur in association with transient lower oesophageal sphincter relaxations not attributable to swallowing. ${ }^{5}$

Findings from recent studies suggest that subclinical partial 'swallows', manifested by feeble mylohyoid activity, may be associated with the onset of lower oesophageal sphincter relaxations associated with gastro-oesophageal reflux of acid..$^{12}$ Although it is possible that subtle mylohyoid activity, not detectable with the methodology used in the present study, may accompany transient lower oesophageal sphincter relaxations, several characteristics distinguish those transient relaxations that accompany most episodes of gastro-oesophageal reflux of gas or acid from those associated with swallowing. Firstly, overt swallowing and pharyngeal activity are generally absent with transient lower oesophageal sphincter relaxations. Secondly, the mean duration of a transient sphincter relaxation associated with gastro-oesophageal reflux of gas is substantially longer $(12 \cdot 3(0 \cdot 4) \mathrm{s})$ than the two to four seconds duration of swallow-induced sphincter relaxation. Although the duration of transient lower oesophageal sphincter relaxations associated with gastro-oesophageal reflux may be caused in part by oesophageal distention during a common cavity episode, those with a long duration may occur in the absence of this. ${ }^{34}$ Lastly, 'mini-swallows', failed dry swallows, or tactile pharyngeal stimulation generally elicit only a partial lower oesophageal sphincter relaxation $^{14}$ compared with the complete relaxation characteristic of the transient lower oesophageal sphincter relaxations associated with gas gastrooesophageal reflux.

The spontaneous transient lower oesophageal relaxations recorded in this study were probably triggered mainly by gastric distention rather than by undetected swallows. Current evidence suggests that gastric distention is a major mechanism for eliciting transient non-deglutitive relaxation of the lower oesophageal sphincter. The gastric distention may be caused by inflation of a gastric balloon,,$^{14}$ feeding, ${ }^{3-5}$ gastric loading with fluid or, as in this study, gastric loading with gas. ${ }^{16}$ The phenotypical patterns of the transient lower oesophageal sphincter relaxations induced by all these types of gastric distention are similar and comparable with those that underlie most spontaneous acid reflux episodes in normal or symptomatic humans. ${ }^{3-5}$

A plausible explanation for the prompting of transient lower oesophageal sphincter relaxation by gastric distention is a neurally-mediated response with a sensory and motor component. The existence of gastric stretch receptors linked to vagal afferents is well established from single vagal fibre recordings in experiments in animals. ${ }^{15} 16$ Vagal motor fibres that elicit lower oesophageal sphincter relaxation have been well defined. ${ }^{17}$ These fibres inhibit the lower oesophageal sphincter via a non-cholinegic, non- adrenergic neurotransmitter and are believed to mediate normal sphincter relaxation associated with swallowing or oesophageal distention. Findings from a recent canine study support the concept of vagal mediation of non-deglutitive transient lower oesophageal sphincter relaxations elicited by gastric distention with air. ${ }^{6}$ In the dog, bilateral cervical vagal blockade induced by cooling abolished the transient lower oesophageal sphincter relaxations and gasinduced gastro-oesophageal reflux elicited by gastric gaseous distention.

This study documents postural regulation of gastric venting of gas but the specific regulatory mechanism was not determined. The increased prevalence of transient lower oesophageal sphincter relaxation and gastro-oesophageal reflux of gas in the upright compared with the recumbent position may be explained by several mechanisms. One possibility is that regional differences in distention of the antrum and gastric fundus may differ in the upright and supine positions. This possibility, however, is not supported by recent findings in the dog. ${ }^{18}$ Another possibility is that extragastric sensory perception of body position influences the neural pathways that mediate transient lower oesophageal sphincter relaxations.

We believe that the results of this study have potential implications for a better understanding of the patho-physiology of symptomatic reflux disease. Findings from recent studies suggest that many patients with reflux oesophagitis have frequent transient lower oesophageal sphincter relaxations that lead to excessive acid reflux. ${ }^{+519}$ The transient sphincter relaxations associated with acid reflux are virtually identical in pattern to those associated with gastro-oesophageal reflux of gas. The similarity in lower oesophageal sphincter relaxation between that associated with gas and acid reflux raises the possibility that these sphincter relaxations may be mediated by the same or a similar mechanism(s). Thus, the transient sphincter relaxations associated with acid reflux may be a variant of the belch reflex.

1 McNally EF, Kelly JE Jr, Ingelfinger FJ. Mechanism of belching: effects of gastric distention with air. Gastroenterology 1964; 64: 254-9.

2 Kahrilas PJ, Dodds WJ, Dent J, Wyman JB, Hogan WJ, Arndorfer RC. Upper esophageal sphincter function during Aelching. Gastroenterology 1986; 91: 133-40.

3 Dent J, Dodds WJ, Friedman RH, et al. Mechanisms of gastroesophageal reflux in recumbent asymptomatic human subjects. F Clin Invest 1980; 65: 256-67.

4 Dodds WJ, Dent J, Hogan WJ, et al. Mechanisms of gastroesophageal reflux in patients with reflux esophagitis. N Engl F Med 1982; 307: 1547-52.

5 Dent J, Holloway RH, Toouli J, Dodds WJ. Mechanisms of lower oesophageal sphincter incompetence in patients with symptomatic gastro-oesophageal reflux. Gut 1988; 29: $1020-8$.

6 Martin CJ, Patrikios J, Dent J. Abolition of gas reflux and transient lower esophageal sphincter relaxation by vagal transient lower esophageal sphincter relaxation by
blockade in the dog. Gastroenterology 1986; $91: 890-6$.

7 Dent J. A new technique for continuous sphincter pressure measurement. Gastroenterology 1976; 71: 263-7.

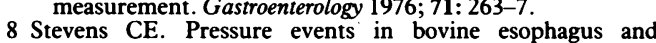
reticulorumen associated with eructation, deglutition and reticulorumen associated with eructation, deglution

9 Winship DH, Zboralske F, Weber WN, Soergel KH.

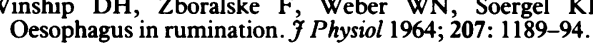

10 Linehan JH, Dent J, Dodds WJ, Hogan WJ. Sleeve device functions as a Starling resistor to record sphincter pressure. Am F Physiol 1985; 248: G251-5.

11 Shaker R, Kahrilas PJ, Dodds WJ, Hogan WJ. Esophagea clearance of small amounts of acid [Abstract]. Gastroenterology 1986; 90: 1628 .

12 Mittal RK, McCallum RW. Characteristics of transient lowe esophageal sphincter relaxation in humans. Am $\mathcal{f}$ Physio 1987; 15: G636-41 
13 Paterson WJ, Rattan S, Goyal RK. Experimental induction of isolated lower esophageal sphincter relaxation in anesthetized possums. F Clin Invest 1986; 77: 1187-93.

14 Holloway RH, Hongo M, Berger K, McCallum RW. Gastric distention: a mechanism for post-prandial gastroesophageal reflux. Gastroenterology 1985; 89: 779-84.

15 Paintal AS. Vagal sensory receptors and their reflex effects. Physiol Rev 1973; 53: 159-227.

16 Falempin M, Mèi N, Rousseau JP. Vagal mechanoreceptors of the inferior thoracic oesophagus, the lower oesophageal the inferior thoracic oesophagus, the lower oesophageal
sphincter and the stomach in the sheep. Pflugers Arch 1978; 373: $25-30$.
17 Goyal RK, Rattan S. Nature of the vagal inhibitory innervation to the lower esophageal sphincter. $\mathcal{F}$ Clin Invest 1975; 55: $1119-26$

18 Little AF, Cox MR, Martin CJ, Franzi J, Dent J. The influence of posture in transient lower oesophageal sphincter relaxation and gastro-oesophageal reflux in the dog. fHepatogastroenterol 1989; 4: 49-54

19 Dent J, Holloway RH, Toouli J, Dodds WJ. Mechanisms of lower oesophageal sphincter incompetence in patients with symptomatic gastro-oesophageal reflux. Gut 1988; 29: symptom. 